\title{
CAPTAÇÃO E CARACTERÍSTICAS DO PRONAF NO COREDE MISSÕES/RS (2013-2018)
}

\author{
FUNDRAISING AND CHARACTERISTICS OF PRONAF IN COREDE \\ MISSÕES/RS (2013-2018)
}

\section{CAPTACIÓN Y CARACTERÍSTICAS DEL PRONAF EN EL COREDE MISSÕES/RS (2013-2018)}

\author{
Dionéia Dalcin ${ }^{1}$ \\ http://orcid.org/0000-0003-1398-1314 \\ Raquel Jaíne Hartmann ${ }^{2}$ \\ http://orcid.org/0000-0002-6146-7240
}

Submissão: 26/04/2020 / Aceito: 28/06/2020

\begin{abstract}
Resumo
A agricultura familiar passou a ser reconhecida a partir da década de 1990, quando as precárias condições sociais e trabalhistas dos pequenos produtores exigiam a intervenção do Estado na construção de políticas públicas adequadas às suas especificidades. Diante deste cenário, originou-se, em 1996, o Programa Nacional de Fortalecimento da Agricultura Familiar (Pronaf). Assim, o objetivo deste estudo foi analisar a captação de recursos e as características dos contratos de custeio e investimento do Pronaf nos municípios do Corede Missões/RS (2013-2018). Adotou-se como metodologia as abordagens quantitativa e descritiva, os dados secundários são oriundos da Matriz de Dados de Créditos Rurais, do Banco Central do Brasil, período 2013-2018, e a análise de dados foi realizada com estatística descritiva. Como resultados, evidencia-se a captação de aproximadamente 67 mil contratos e 1,5 bilhões de reais na modalidade custeio, sendo que os principais produtos foram grãos e bovinos, com destaque para os municípios de Giruá e São Paulo das Missões. $\mathrm{Na}$ modalidade investimento, foram captados aproximadamente 27 mil contratos e 500 milhões de reais, sendo que os principais produtos foram bovinos e máquinas e implementos, destacando-se os municípios de Porto Xavier e Giruá. De forma geral, existem desigualdades na captação e características do Pronaf nos municípios do Corede Missões, dados semelhantes aos demais municípios do Rio Grande do Sul. Por fim, retratase o Pronaf como uma política pública que vem favorecendo o Corede Missões, com injeção de recursos para a agricultura familiar e democratizando o acesso ao crédito com o intuito de favorecer o meio rural.
\end{abstract}

Palavras-chave: Custeio. Investimento. Setor Agropecuário.

\footnotetext{
${ }^{1}$ Doutora em Agronegócios pela Universidade Federal do Rio Grande do Sul (UFRGS), docente da Universidade Federal da Fronteira Sul (UFFS), campus Cerro Largo. Programa de Pós-Graduação em Desenvolvimento e Políticas Públicas. E-mail: dioneia.dalcin@uffs.edu.br

${ }^{2}$ Bacharel em Administração pela Universidade Federal da Fronteira Sul (UFFS), campus Cerro Largo. E-mail: raquelhartmann4@gmail.com
}

DOI: http://dx.doi.org/10.22295/grifos.v30i51.5415 | Edição Vol. 30, Núm. 51, 2021. 


\begin{abstract}
Family farming was first recognized in the 1990s due to poor social and working conditions of small-scale farmers, who demanded the State intervention in the creation of adequate public policies to their specificities. For this reason, in 1996 the Programa Nacional de Fortalecimento da Agricultura Familiar (Pronaf) was implemented. Therefore, the objective of this study was to analyze both the fundraising and the characteristics of the funding and investment contracts of Pronaf in the cities that belong to Corede Missões/RS (2013-2018). The quantitative and descriptive approaches were selected as methodology; secondary data were collected on the Matriz de Dados de Créditos Rurais from Banco Central do Brasil, 2013 - 2018 period, and data analysis was conducted with descriptive statistics. Results show the fundraising of approximately 67 thousand contracts and 1.5 billion of reais for the funding category, in which the main products funded were grain and cattle, especially in the cities of Giruá and São Paulo das Missões. In the investment category, 27 thousand contracts and 500 million of reais were funded: the main products were cattle and machinery and implements, and the main receivers were the cities of Porto Xavier and Giruá. In general, in the cities of Corede Missões, inequalities in the fundraising and in the characteristics of Pronaf were perceived. Similar data were also found in most cities of Rio Grande do Sul. Finally, Pronaf is a public policy that has been bringing benefits to Corede Missões, since it funds family farming and democratizes access to credit in order to favor rural areas.
\end{abstract}

Keywords: Funding. Investment. Agriculture Sector.

\title{
Resumen
}

La agricultura familiar comenzó a ser reconocida en la década de 1990, cuando las precarias condiciones sociales y laborales de los pequeños productores exigían la intervención del Estado en la construcción de políticas públicas adecuadas a sus especificidades, dado este escenario, se originó, en 1996, el Programa Nacional para el Fortalecimiento de la Agricultura Familiar (Pronaf). Así, el objetivo de este estudio fue analizar la captación de recursos y las características de los contratos de costeo e inversión de Pronaf en los municipios del Corede Missões/RS (2013-2018). Se adoptó como metodología el enfoque cuantitativo y descriptivo, los datos secundarios provienen de la Matriz de Datos de Crédito Rural, del Banco Central de Brasil, período 2013-2018, y el análisis de datos se realizó con estadística descriptiva. Como resultado, fue evidente que se obtuvieron cerca de $67 \mathrm{mil}$ contratos, 1.500 millones de reales en la modalidad de costeo y los principales productos fueron granos y ganado, con énfasis en los municipios de Giruá y São Paulo das Missões. En la modalidad de inversión, la captación fue de aproximadamente 27 mil contratos y 500 millones de reales, y los principales productos fueron ganado y maquinaria e implementos, con énfasis en los municipios de Porto Xavier y Giruá. En general, existen desigualdades en la captación y características de Pronaf en los municipios del Corede Missões, datos similares a otros municipios en Rio Grande do Sul. Finalmente, Pronaf se representa como una política pública que ha favorecido a Corede Missões, con inyección de recursos para la agricultura familiar y democratizando el acceso al crédito con el objetivo de favorecer el medio rural.

Palabras clave: Costeo. Inversión. Sector agropecuario. 


\section{INTRODUÇÃO}

A vocábulo agropecuária é utilizado para designar a pecuária e a agricultura, sendo que a pecuária está diretamente ligada à criação de animais, ao passo que a agricultura está ligada às técnicas no cultivo de plantas e hortaliças. A agropecuária está dividida em patronal e familiar. A primeira, é voltada para a mão de obra assalariada, visto que o trabalhador não é o proprietário das terras. Na agropecuária familiar, o gerenciamento da propriedade e a realização das atividades é feito por um grupo familiar, podendo ele ser ou não o proprietário da terra (KAGEYAMA, 2008).

Atualmente, o debate sobre a agricultura familiar vem adquirindo autenticidade em âmbito social, político e acadêmico no Brasil. Conforme a Lei $\mathrm{N}^{\mathrm{o}} 11.326$, de 24 de Julho de 2006, que estabelece as diretrizes para a formulação do Programa Nacional de Fortalecimento da Agricultura Familiar e Empreendimentos Familiares Rurais, é considerado agricultor e empreendedor familiar, o produtor que atende aos requisitos de não possuir área maior de quatro módulos fiscais, que utilize mão de obra predominantemente da família, tenha um percentual mínimo de renda promovida pelas atividades exercidas na propriedade ou empreendimento familiar e que dirige e gerencia sua propriedade com a família (BRASIL, 2006).

Já as políticas públicas, são ações criadas pelos governos para atender às necessidades e interesses da sociedade. Para Marques, Siedenberg e Santos (2008), as políticas públicas buscam satisfazer demandas, em especial, das esferas sociais que costumam ser excluídas, ou vulneráveis. As reivindicações são analisadas pelos governantes, no entanto, são decorrentes da pressão e mobilização coletiva. Schneider e Grisa (2015) relatam que se tornaram, a partir do reconhecimento da agricultura familiar, ainda mais visíveis as precárias condições sociais e trabalhistas dos pequenos produtores e, cada vez mais, evidenciou-se a indispensabilidade da intervenção do Estado na construção de políticas públicas adequadas às suas especificidades.

Como consequência da necessidade de políticas voltadas para agricultura familiar, desponta o Programa Nacional de Fortalecimento da Agricultura Familiar (Pronaf), criado em 1996 por meio da Secretaria de Agricultura Familiar (SAF), tendo por objetivo financiar projetos para os agricultores (BATISTA; NEDER, 2014). Os autores ainda destacam que o 
programa buscava atender às necessidades dos agricultores familiares, a fim de aprimorar suas propriedades e técnicas de trabalho, considerando que a escassez de recursos e a baixa produtividade não lhes permitia investimentos em modernização diante aos preços estipulados pelo mercado.

Tendo em vista as observações a respeito da caracterização do Pronaf, o Banco Central do Brasil (2017) apresenta o programa com 12 linhas de crédito que permitem ampliar a produção, modificar e modernizar as atividades, além de incentivar o constante desenvolvimento rural por meio de financiamentos de investimento, custeio e comercialização.

Nesse contexto, o Pronaf foi criado para promover o desenvolvimento rural, de forma que fosse possível amenizar as desigualdades regionais e entre os tipos de agricultores. Entretanto, conforme Souza et al. (2013), apesar de representar uma conquista do segmento familiar, o Pronaf não tem conseguido eliminar as desigualdades regionais e acaba por favorecer a agricultura familiar em alguns segmentos e locais específicos como, por exemplo, a região Sul. Os dados da análise realizada por Brambilla e Michellon (2017) demonstram que, até o censo agropecuário de 2006, a região sul recebeu mais recursos que as demais, ou seja, obteve $41 \%$ do valor repassado, enquanto a segunda com maior valor recebido é a região Nordeste com 26\%; a terceira região que mais ganhou recursos é região Sudeste com 19\% do valor; a quarta com o maior valor é a região Norte com $8 \%$ e a região que obteve o menor repasse foi o Centro-Oeste, com $6 \%$ do valor total repassado.

Dentro da temática de distribuição dos contratos e recursos do Pronaf, considerando a captação de fundos pelo Rio Grande do Sul, um estudo realizado por Dalcin et al. (2017) analisou a captação de recursos e contratos do Programa Nacional de Fortalecimento da Agricultura Familiar (Pronaf) por Conselhos Regionais de Desenvolvimento (Coredes) do estado do Rio Grande do Sul. Nesse estudo, foi possível identificar os Coredes que se destacam em termos de contratação e recursos. Além disso, observou-se que dos 28 Coredes no RS, nove obtêm aproximadamente $60 \%$ do montante total de recursos do estado, sendo eles, respectivamente: o Corede Norte, Fronteira Noroeste, Rio da Várzea, Serra, Nordeste, Alto do Jacuí, Missões, Celeiro e Produção. Dessa forma, o estudo teve como objetivo analisar a captação de recursos, bem como as características dos contratos de custeio e investimento do Pronaf nos municípios do Corede Missões/RS (2013-2018). Desse modo, 
escolheu-se estudar o Corede Missões, que é um dos 28 Coredes do Estado do Rio Grande do Sul (FEE, 2013) e, entre 2013 e 2016, captou um total de 66.361 contratos do PRONAF, sendo o $7^{\circ}$ maior Corede em relação à captação de recursos para o período ( $\mathrm{R} \$ 1.2$ bilhões) (BANCO CENTRAL DO BRASIL, 2017). Em 2012, o Corede Missões apresentou um Produto Interno Bruto (PIB) de aproximadamente R \$ 4,6 bilhões, o que representava 1,6\% do total do Estado. O PIB per capita era de R $\$ 18.581,00$, abaixo da média do Estado (R\$ $25.779,00)$, o que o colocava na $19^{\circ}$ posição entre os 28 Coredes (FEE, 2015).

Segundo a Fundação de Economia e Estatística - FEE (2015), o Corede Missões possui como base econômica à agropecuária, com pouca participação da indústria. Em relação à agropecuária, são destacadas a criação de bovinos, suínos, o cultivo do milho, do trigo e da mandioca. A indústria, que se apresenta pouco significativa, está ligada ao beneficiamento de produtos primários. Outro importante ativo da região é o turismo histórico e cultural. Os dados do Governo do Estado do Rio Grande do Sul (2017) evidenciam que a região do Corede Missões alcançou, em 2013, um VAB total de R $\$ 5,89$ bilhões, decorrendo em um crescimento absoluto de 56,36\% em relação ao ano de 2010. Nesse mesmo período, a região demonstrou um incremento absoluto de $81,26 \%$ na geração de valor agropecuário, atingindo um montante de $\mathrm{R} \$ 1,74$ bilhão. No tocante ao ano de 2014, os principais produtos agropecuários cultivados na região das Missões foram a soja, responsável por uma produção de 1,197 milhão de toneladas, aproximadamente $10 \%$ do total estadual; o milho, que representou $6 \%$ de toda geração do estado, com um montante de produção na ordem de 332 mil toneladas; o trigo teve um volume de 253 mil toneladas, representando $15 \%$ da produção do estado, enquanto a produção de cana-de-açúcar (174 mil toneladas) e o leite (250 milhões de litros) tiveram uma representatividade de $56 \%$ e $20 \%$ e, $5 \%$ do total do montante do estado gaúcho. Outro fator de importante geração e de renda, refere-se à criação de bovinos que alcançou, em 2014, um montante na ordem de 786.560 cabeças, correspondente a 5,64\% do rebanho no estado do Rio Grande do Sul. Quanto às agroindústrias familiares, $72 \%$ do número total de municípios da região possuem até 10 agroindústrias e $20 \%$ apresentam entre 11 a 20 agroindústrias. 


\section{METODOLOGIA DA PESQUISA}

A pesquisa é caracterizada como descritiva, uma vez que, conforme Gil (2008), tem como objetivo principal a descrição das características de determinada população, fenômeno ou as relações entre determinadas variáveis. No estudo proposto, objetivou-se descrever os dados do Pronaf para o Corede Missões. Para tanto, foram utilizados dados secundários coletados por intermédio da Matriz de Dados do Crédito Rural do Banco Central do Brasil BCB.

A população do estudo é composta por contratos e recursos para o Pronaf Custeio e Investimentos dispostos na Matriz de Dados do Crédito Rural do Banco Central do Brasil BCB (2019), referente aos anos de 2013 a 2018. A delimitação do período provém do fato de que a Matriz passou a ser disponibilizada a partir do ano de 2013, sendo que as informações do último ano completo fazem menção ao ano de 2018. A coleta de dados para a efetivação deste estudo foi feita por meio de planilhas da Matriz de Dados de Créditos Rurais dispostas no site do Banco Central do Brasil, no seguinte link: https://www.bcb.gov.br/. Tal matriz disponibiliza diversas informações em relação ao Pronaf, entre elas, as que serão utilizadas para a concretização do objetivo estabelecido neste estudo: a) a quantidade e o valor dos contratos por município; b) quantidade e valor dos contratos de custeio e investimento por produto, nas atividades agrícola e pecuária.

A análise dos dados foi realizada por meio da plataforma Calc LibreOffice quando foram tabulados e organizados e, a partir disso, foi possível desenvolver análises estatísticas descritivas. Desse modo, a tabulação tem como objetivo básico sintetizar uma série de valores, permitindo que se tenha uma visão global da variação desses valores. Esse tipo de análise organiza e descreve os dados de três maneiras: por meio de tabelas, de gráficos e de medidas descritivas (GUEDES et al., 2005).

Por fim, foram realizados cálculos de média em relação aos valores dos contratos quanto à frequência dos produtos financiados e comparativos entre os anos, com o intuito de identificar as principais variações ocorridas no período estudado. 


\section{O PRONAF CUSTEIO E INVESTIMENTO NO COREDE MISSÕES}

\section{Custeio e Investimento agrícola}

O custeio agrícola é um benefício concedido aos produtores rurais, pessoa física ou jurídica, destinado para custear as despesas de lavouras de safra, entressafra de lavouras permanentes ou da extração de produtos vegetais ou cultivos, tais como industrialização dos produtos, produção de mudas ou sementes, insumos, colheitas, entre outras finalidades (BANCO CENTRAL DO BRASIL, 2017). De acordo com o mesmo autor, no período entre 2013 e 2018, as regiões brasileiras captaram cerca de 2 milhões de contratos e aproximadamente 44 bilhões de reais em custeio agrícola, ou seja, foram captados em média 368.564 contratos por ano, sendo que a média de valor por contrato foi de R \$19.897,01. Já o investimento agrícola é descrito como uma linha de financiamento para aquisição de bens, máquinas e equipamentos, construção ou reforma de galpões, armazéns e implementos e para plantio de culturas (BANCO CENTRAL DO BRASIL, 2017). Para o Banco Central do Brasil (2017), durante o período delimitado por tal estudo (2013-2018), foram captados aproximadamente 1,7 milhão de contratos e cerca de 26 bilhões em recursos em todo território brasileiro. A média de captação apresentou cerca de 292 mil contratos por ano e aproximadamente 4,3 bilhões de reais.

Os dados de captação dos contratos, custeio e investimento agrícola entre os municípios do Corede Missões (Gráfico 1 e 2) demonstram a desigualdade no número de contratos entre os municípios, bem como o valor captado, sendo aproximadamente 67 mil contratos e 1,5 bilhão de reais em custeio e investimento.

O Gráfico 1 demonstra que o município que mais captou contratos (6.365 e 1.156) de custeio e investimento agrícola foi Giruá, e o que efetuou o menor número de contratações de custeio foi Garruchos, com 372 contratações e, em investimentos, foi Dezesseis de Novembro (119). A média de contratações de custeio agrícola na Região das Missões foi de 375,5 por município ao ano, superior à média do estado (303,8 contratos por município). A média de contratos de investimento captados por município foi de 67 contratos, número semelhante ao do estado (68 contratos por município). Para Olalde, 
Santos e Santos (2007), as contratações diferem a partir das especificidades de cada local e de fatores como tipo de produção, área plantada, clima, entre outros.

Gráfico 1- Número de contratos agrícolas nos Municípios do Corede Missões (2013-2018)

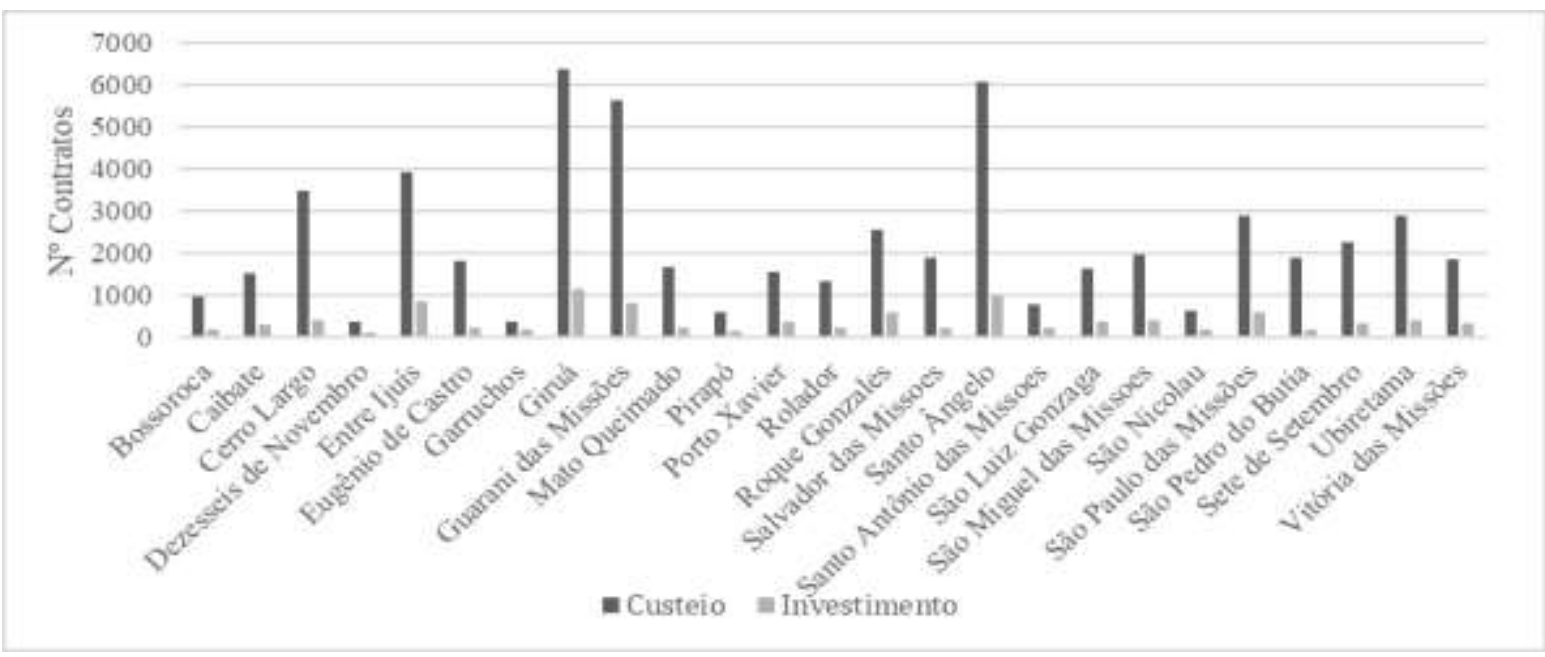

Fonte: Elaborado pelos autores (2020).

Gráfico 2 - Valor total captado para custeio e investimento agrícola (2013-2018)

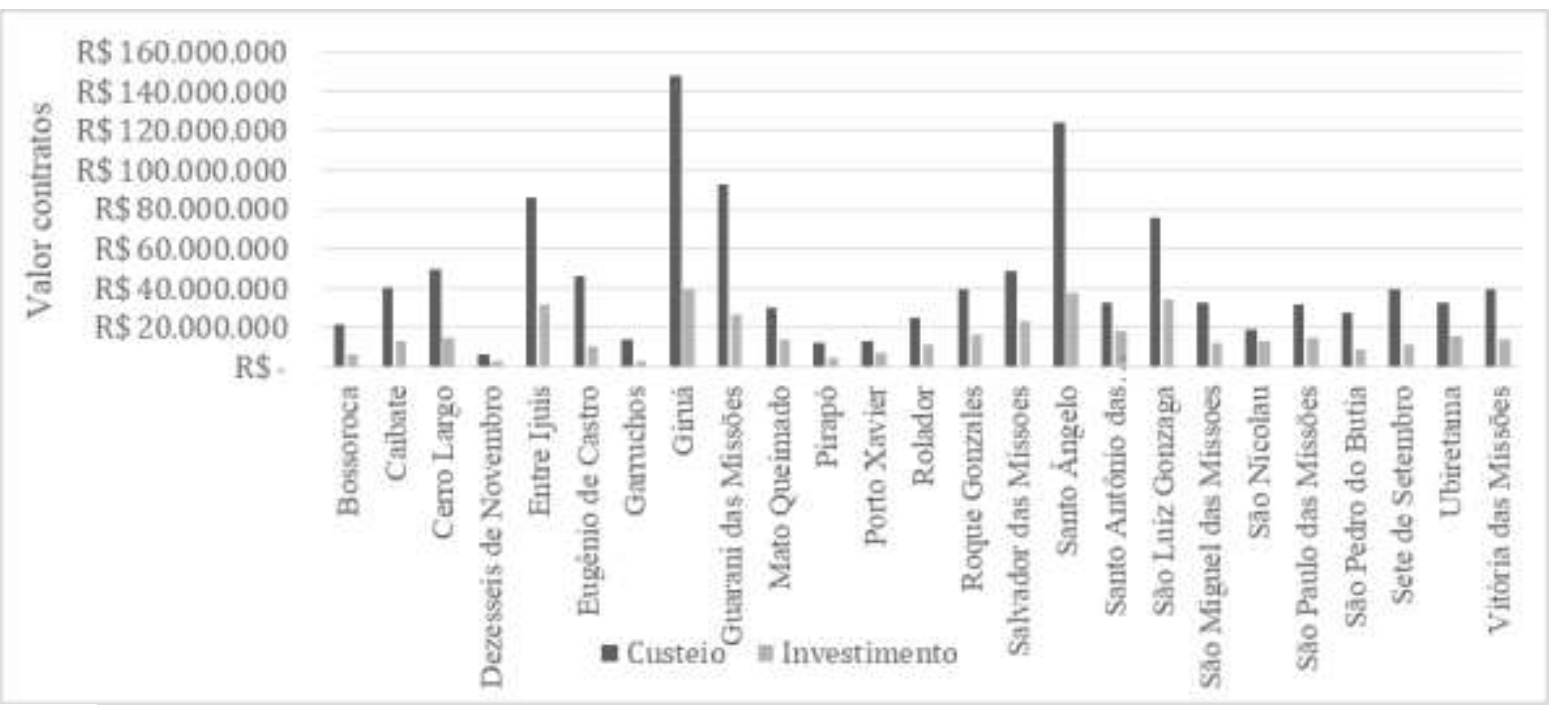

Fonte: Elaborado pelos autores (2020).

No Gráfico 2, Giruá foi o município que mais captou recursos de custeio e investimento agrícola no período estabelecido, aproximadamente 148 milhões de reais e 39 milhões respectivamente. Já o município que menos acessou os recursos do Pronaf custeio foi Dezesseis de Novembro, com 6 milhões, sendo que Garruchos captou o menor valor em 
recursos de investimento (2 milhões). Spolandor e Lima (2009) destacam que os custeios agrícolas e a distribuição dos recursos desta modalidade estão diretamente relacionados com a produção de lavoura temporária. Dessa forma, a grande captação de recursos de custeio agrícola por Giruá pode estar relacionada com a produtividade de soja e de milho, que, segundo a Prefeitura Municipal de Giruá, em 2019, apresentou as maiores safras da série histórica do município registradas pelo levantamento sistemático da produção agrícola, pesquisa realizada pelo IBGE desde 1972.

O Gráfico 3 destaca os valores totais captados anualmente no Corede Missões em custeio e investimento agrícola, para o período de 2013 a 2018. Identifica-se a variação dos valores captados no Corede Missões durante os anos analisados, assim como a variação para custeio que foi de aproximadamente 20 milhões e de 26 milhões para investimento. Valores que são distribuídos de forma desigual entre os municípios, mas que tendem a auxiliar no desenvolvimento econômico das famílias beneficiadas, bem como no aprimoramento das produções.

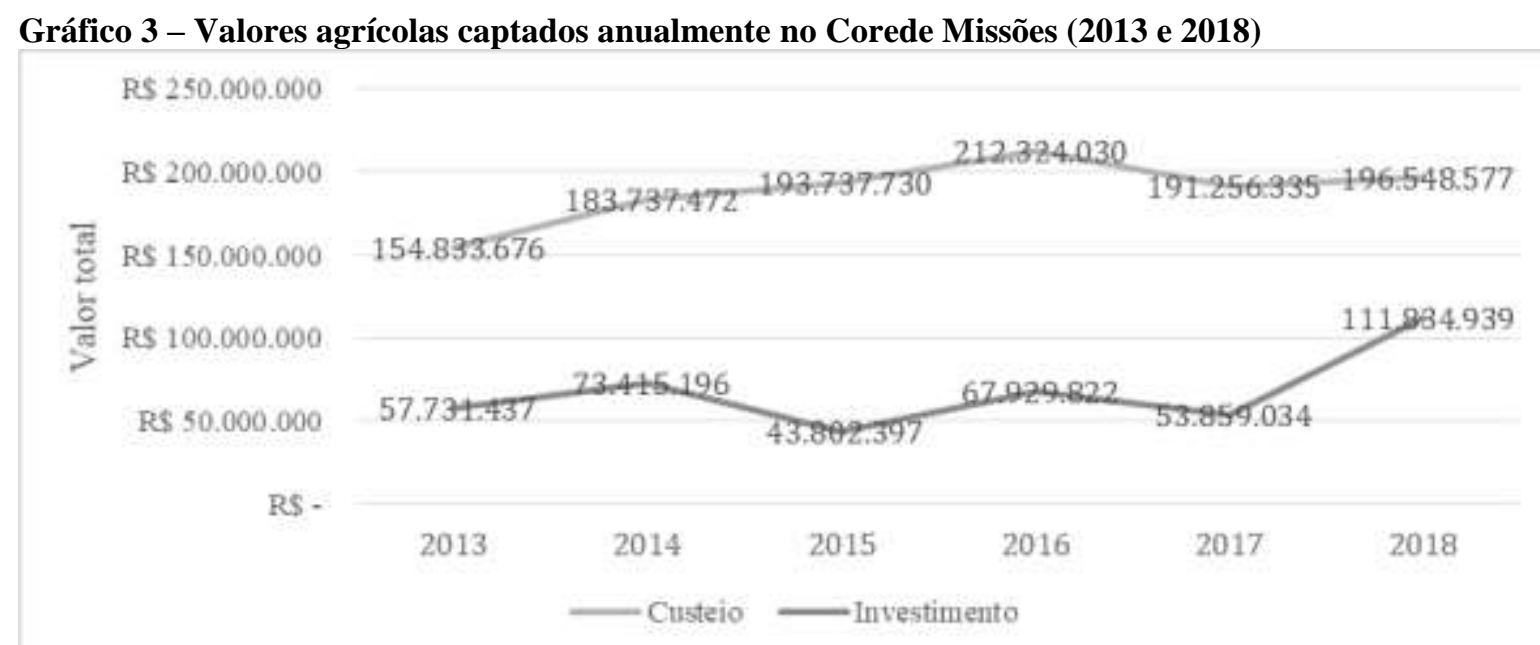

Fonte: Elaborado pelos autores (2020).

Com base nos dados supracitados, número de contratos, valores e município, pode-se observar que, para recursos de custeio, a média anual foi de 188 milhões, sendo a média por contrato de $\mathrm{R} \$ 20.102,57$. E a média de captação por município no Corede Missões foi 7,5 milhões por ano, sendo que a média de valor captado anualmente no estado do Rio Grande do Sul, no mesmo período, foi de 2,7 bilhões de reais por município. Já para os recursos 
captados em investimento, por ano nos municípios do Corede Missões, foi de 68 milhões de reais, sendo o valor médio por município de 2,7 milhões. E a média de contratação de recursos anuais do estado ficou próxima a 1,2 bilhões de reais e a média de contratação por município em cada ano, ficou 2,4 milhões. Os dados mostram que os municípios analisados captam menos que a média do estado, o que reflete no fato de a região ter um indicador socioeconômico médio. Em 2016, tal indicador foi de 0,742 , colocando a região na $17^{\circ}$ posição entre os Coredes (FEE, 2020).

Após o panorama geral de contratos e valores captados para o setor agrícola, procurou-se conhecer os produtos que foram contratados para custeio e investimento agrícola. As Tabela 1 e Tabela 2 apresentam os principais produtos financiados para custeio agrícola, o número de contratos e valores, respectivamente.

Tabela 1- Produtos Versus número de contratos (2013 a 2018) para custeio agrícola

\begin{tabular}{cccccccc}
\hline Produtos & 2013 & 2014 & 2015 & 2016 & 2017 & 2018 & Total \\
\hline Soja & 5.191 & 5.196 & 5.096 & 4.853 & 4.625 & 4.330 & 29.291 \\
Trigo & 2.287 & 2.788 & 2.370 & 1.974 & 2.045 & 1.760 & 13.224 \\
Milho & 2.756 & 2.240 & 2.000 & 2.433 & 1.650 & 1.638 & 12.717 \\
Outros & 139 & 120 & 137 & 144 & 249 & 312 & 1.101 \\
\hline Total & 10.373 & 10.344 & 9.603 & 9.404 & 8.569 & 8.040 & 56.333 \\
\hline
\end{tabular}

Outros: Cana-de-açúcar, Mandioca, Canola, Girassol, Aveia, Melancia, Morango, Melão, Linho, Alfafa, ocultos $^{3}$.

Fonte: Elaborado pelos autores (2020).

Tabela 2 - Produtos Versus valor captado (2013 a 2018) para custeio agrícola (em mil)

\begin{tabular}{lccccccc}
\hline Produtos & $2013 / \mathrm{R} \$$ & $2014 / \mathrm{R} \$$ & $2015 / \mathrm{R} \$$ & $2016 / \mathrm{R} \$$ & $2017 / \mathrm{R} \$$ & $2018 / \mathrm{R} \$$ & Total/R $\$$ \\
\hline Soja & 76.186 & 88.889 & 102.946 & 119.478 & 117.955 & 124.432 & 510.411 \\
Trigo & 44.024 & 62.438 & 54.924 & 48.814 & 48.593 & 44.803 & 303.599 \\
Milho & 19.766 & 17.961 & 19.124 & 30.023 & 19.683 & 24.191 & 130.751 \\
Oculto & 12.812 & 13.441 & 15.732 & 12.426 & 1.363 & 795 & 56.571 \\
Cana-de- & 930 & 808 & 619.336 & 556 & 300 & 417 & 3.013 \\
açúcar & 64 & 198 & 389 & 1.044 & 220 & 3.903 & 5.821 \\
Outros & 153.783 & 183.737 & 812.455 & 92.866 & 188.118 & 198.544 & 1.010 .168 \\
\hline Total & 153.04
\end{tabular}

Outros: Mandioca, Canola, Girassol, Aveia, Melancia, Morango, Melão, Linho, Alfafa, ocultos.

Fonte: Elaborado pelos autores (2020).

\footnotetext{
${ }^{3}$ De acordo com o Banco Central do Brasil (2017), para preservação do sigilo bancário (LC 105/2001), em nível de município, os produtos com até três contratos estão ocultos.

DOI: http://dx.doi.org/10.22295/grifos.v30i51.5415 | Edição Vol. 30, Núm. 51, 2021.
} 
As Tabelas 1 e 2 evidenciam que os grãos $(98,04 \%)$ são os principais produtos financiados para custeio, sendo que a soja soma $52 \%$ (29.291) dos contratos destinados à produção e comercialização, totalizando um valor de 500 milhões. O município que mais contratou custeios de soja foi Giruá, com 3.581 contratos ( $\mathrm{R} \$ 86.564 .402,80)$, seguido de Santo Ângelo ( $\mathrm{R} \$ 79.356 .467,50)$, com 3.575 contratos e Entre Ijuís (R\$53.133.333,20), com 2.165 contratos. Para a Prefeitura Municipal de Giruá (2019), o município é configurado como um dos maiores municípios gaúchos em extensão de área, possuindo 2.875 imóveis rurais e uma área total de 82.406,1 hectares, sendo que 67 mil hectares são agricultáveis.

O trigo, segundo produto de maior expressão, representa 23,47\% (13.224) dos contratos, aproximadamente 300 milhões custeados. Novamente o município com maior número de contratos em custeios agrícolas para plantação e comercialização de trigo foi Giruá, com 1.784 contratos $(\mathrm{R} \$ 45.123 .810,10)$. O segundo município a contratar mais custeios de trigo foi Santo Ângelo, com 1.452 contratos (R\$33.801.199, 10), seguido por Guarani das Missões, que contratou 1.404 (R $\$ 27.304 .795,30)$. E o milho é o terceiro produto custeado, 22,57\% (12.717) contratos, financiando cerca de 130 milhões. Cerro Largo figura como o município que efetuou o maior número de contratos para custeio de milho, foram 1.237 contratações (R $\$ 9.566 .938,83$ ), seguido por São Paulo das Missões, com 1.195 contratos (R\$9.324.960,49), e Guarani das Missões, com 1.107 contratos custeando as atividades relacionadas ao milho ( $\mathrm{R} \$ 9.626 .574,68)$.

São destacados entre os outros produtos a cana-de-açúcar (266 contratos), concentrados nos municípios de Roque Gonzáles e Porto Xavier. De acordo com Barbosa, Alves e Massuquetti (2013), regiões das Missões e Médio Alto Uruguai são responsáveis pela produção mais significativa de cana-de-açúcar do estado, em especial os municípios de Roque Gonzáles, com um total de 77.000 toneladas e Porto Xavier, com 33.600 toneladas, produto que representa a diversidade da agricultura familiar.

Assim, evidencia-se a relevância do custeio agrícola para o Corede Missões, pois, de 2013 a 2018, foram efetivados 56.333 contratos em custeio agrícola e cerca de 1 bilhão de reais, em especial para a produção de grãos. Ademais, o Corede Missões captou na modalidade custeio agrícola aproximadamente $2,2 \%$ do valor total captado em todo 
território brasileiro, demonstrando que o Pronaf tem, de fato, auxiliado nas atividades da agricultura familiar do Corede Missões, principalmente na produção de grãos.

As Tabela 3 e Tabela 4 apresentam os principais produtos financiados em investimento agrícola, o número de contratos e valores, respectivamente.

Tabela 3 - Produtos versus número de contratos (2013 a 2018) para investimento agrícola

\begin{tabular}{cccccccc}
\hline Produtos & 2013 & 2014 & 2015 & 2016 & 2017 & 2018 & Total \\
\hline Outras Máquinas & 633 & 602 & 406 & 446 & 6 & & 2.093 \\
Máquinas e implementos & 579 & 106 & 81 & 51 & 473 & 642 & 1.932 \\
Trator & 178 & 299 & 214 & 231 & 257 & 391 & 1.570 \\
Oculto & 299 & 246 & 208 & 212 & 241 & 274 & 1.480 \\
Outros & 1.508 & 360 & 194 & 216 & 276 & 500 & 3.054 \\
\hline Total & 3.197 & 1.613 & 1.103 & 1.156 & 1.253 & 1.807 & 10.129 \\
\hline
\end{tabular}

Outros: Proteção de solo, Correção Intensiva do Solo, Residências Rurais, Camionetas, Depósitos e instalações, Melhoramentos, Reformas de aparelhos, Irrigação, Cana-de-açúcar, Colheitadeira, entre outros.

Fonte: Elaborado pelos autores (2020).

Tabela 4 - Produtos versus valor captado (2013 a 2018) para investimento agrícola (em mil)

\begin{tabular}{lccccccc}
\hline Produtos & $2013 / \mathrm{R} \$$ & $2014 / \mathrm{R} \$$ & $2015 / \mathrm{R} \$$ & $2016 / \mathrm{R} \$$ & $2017 / \mathrm{R} \$$ & $2018 / \mathrm{R} \$$ & Total \\
\hline Trator & 13.548 & 19.718 & 11.704 & 13.1667 & 15.345 & 26.867 & 100.350 \\
Oculto & 8.297 & 16.710 & 9.085 & 25.145 & 10.482 & 14.480 & 84.202 \\
Máquinas e implementos & 6.157 & 3.166 & 2.216 & 1.966 & 15.345 & 40.968 & 69.821 \\
Proteção de solo & 947 & 16.710 & 9.085 & 25.145 & 10.482 & & 62.370 \\
Outras Máquinas & 14.825 & 18.577 & 10.882 & 16.609 & 240 & & 61.135 \\
Depósitos e instalações & 18.693 & 3.002 & 2.184 & 1.727 & 2.563 & 3.812 & 29.800 \\
Colheitadeira & & 2.365 & 4.059 & 4.430 & 6.449 & 14.097 & 24.952 \\
Correção Intensiva do Solo & 4.449 & 1.348 & 1.236 & 2.273 & 2.610 & 5.923 & 16.606 \\
Outros & 6.786 & 5.971 & 1.302 & 2.560 & 1.063 & 5.685 & 23.369 \\
\hline Total & 73.705 & 87.570 & 51.756 & 93.025 & 64.585 & 29.519 & 472.610 \\
\hline Outros: Resic
\end{tabular}

Outros: Residências Rurais, Camionetas, Depósitos e instalações, Melhoramentos, Reformas de aparelhos, Irrigação, Cana-de-açúcar, entre outros.

Fonte: Elaborado pelos autores (2020).

As Tabelas 3 e 4 evidenciam que o maior número de contratos captados é destinado para opção "outras máquinas", com 2.093 contratos e cerca de 61 milhões em recursos adquiridos. Entre Ijuís é o município que mais captou contratos nessa modalidade, foram 231 contratações e aproximadamente 6,4 milhões financiados, seguido de Giruá, com 229 contratações e 6 milhões em recursos, e Santo Ângelo é o terceiro município a adquirir mais contratos para máquinas, ou seja, foram 178 contratações e 4,8 milhões em financiamentos.

DOI: http://dx.doi.org/10.22295/grifos.v30i51.5415 | Edição Vol. 30, Núm. 51, 2021. 
As Máquinas e implementos estão em segundo lugar na captação de investimentos com 1.932 contratos e mais de 60 milhões de reais. O município que mais captou contratos foi Giruá, com 211 contratações e 6 milhões, seguido de Santo Ângelo, com 191 contratos e 6,4 milhões, e de Guarani das Missões, com 182 contratos e 5,4 milhões de reais.

Ainda conforme Tabela 3, o trator é o terceiro produto que mais foi financiado com 1.570 contratos e cerca de 100 milhões de reais. Os municípios que mais adquiriram tratores por meio de investimento agrícola foram Giruá e Santo Ângelo, com 172 contratos, ambos com aproximadamente 10 milhões de reais cada, seguidos de Guarani das Missões, com 153 contratos e 8,9 milhões de reais, próximo de Entre Ijuis, com 126 contratos e um valor financiado de 8,2 milhões. É possível analisar que, apesar de o número de contratos destinados a compra de tratores ter sido inferior aos contratos de compra de outras máquinas e implementos, os recursos emitidos foram consideravelmente elevados, o que demonstra que o valor médio por contrato captado para a obtenção de trator é superior, ou seja, o valor médio dos contratos destinados a compra de tratores ficou em torno de 64 mil reais. Já a média de valor por contrato para a compra de máquinas e implementos, aproximou-se de 31 mil reais e, para a compra de outras máquinas, girou em torno de 29 mil reais.

Foram custeadas também outras atividades agrícolas relacionadas com a correção e proteção do solo, por exemplo. Foram feitas 1.216 contratações destinadas a essas duas finalidades. Por meio dos recursos de investimento agrícola foram adquiridas camionetas, carretas, jipes, reboques, motocicletas e outros veículos. Um total de 210 contratos chegou a ser destinado para a compra destes produtos e um valor aproximado de 7 milhões em financiamentos. Ademais, captaram-se 451 contratações e cerca de 16 milhões em recursos para a construção de depósitos e armazéns. Tal como descrito por Silva (2006), por intermédio do custeamento desse tipo de instalação, o Pronaf procura auxiliar os agricultores e cooperativas no armazenamento, beneficiamento ou industrialização dos produtos e insumos agropecuários, bem como de máquinas e implementos agrícolas. Destaca-se que os contratos de investimento foram destinados ao melhoramento das atividades agrícolas, reformas de máquinas e veículos, compra de peças e acessórios, além de construções e recuperação de barragens, tanques, sistemas de captação de água como poços artesianos e cisternas e eletrificação e irrigação. 
Diante disso, observou-se a grande representatividade de investimentos agrícolas no Corede Missões por meio dos resultados que foram captados, ou seja, 10.129 contratos e absorvidos cerca de 472 milhões em recursos. A média de contratos foi de 1.688 por ano e o valor por contrato ficou em torno de $\mathrm{R} \$ 11.041,06$, sendo que os principais produtos adquiridos foram máquinas, implementos e tratores. Além do mais, a Região das Missões captou no período analisado, cerca de $1,8 \%$ do valor total captado na modalidade de investimento agrícola, em todo país.

Os dados de custeio e investimento para os produtos agrícolas reforçam a disparidade entre os municípios e, até mesmo, entre os tipos de produtos beneficiados pelo programa. Os produtos mais financiados estão ligados à monocultura e às atividades para agricultores patronais, sendo também cultivados por agricultores familiares.

\section{Custeio e investimento pecuário}

O custeio pecuário promove o custeio de despesas com insumos, tratos culturais e colheita do ciclo produtivo da lavoura, assim como a produção de mudas, sementes certificadas e fiscalizadas (BANCO CENTRAL DO BRASIL, 2017). Para o mesmo autor, no período entre 2013 e 2018, foram captados mais de 1 milhão de contratos e cerca de 22 bilhões de reais na modalidade de custeio pecuário no Brasil, ou seja, a média anual de contratos ficou em torno de 167 mil contratos por ano, sendo que o valor médio por contrato se aproximou de 22 mil reais. Já o investimento pecuário pode ser visto como uma linha de financiamento para aquisição de animais para reprodução, cria ou serviço e reprodutores. Além do mais, auxilia na formação, reforma ou recuperação de pastagens; aquisição de máquinas e equipamentos e construções rurais (MINISTÉRIO DA AGRICULTURA, PECUÁRIA E ABASTECIMENTO, 2019). De acordo com Banco Central do Brasil (2017), foram captados mais de 4,6 milhões de contratos e cerca de 41 bilhões na modalidade de investimento pecuário, entre 2013 e 2018, em todo Brasil. A média de contratos captados por ano ficou em torno de 766 mil, e a média de recursos de 6,8 bilhões por ano.

Os recursos disponibilizados pelo Pronaf foram direcionados, na maioria das vezes, ao custeio e investimento agrícola. No entanto, nos últimos anos observa-se o crescimento dos valores aplicados em contratos de custeio e investimento pecuário. Além do mais, os 
financiamentos destinados a esta finalidade têm registrado estabilidade de captação (CAPELLESSO; CAZELLA; BÚRIGO, 2018).

Os Gráfico 4 e 5 identificam a quantidade de contratos captados e valor captado em cada município do Corede Missões, para a modalidade de custeio e investimento pecuário, sendo que foram aproximadamente 27 mil contratos e 500 milhões de reais. Enfatizando, ainda, uma distribuição desigual entre os municípios.

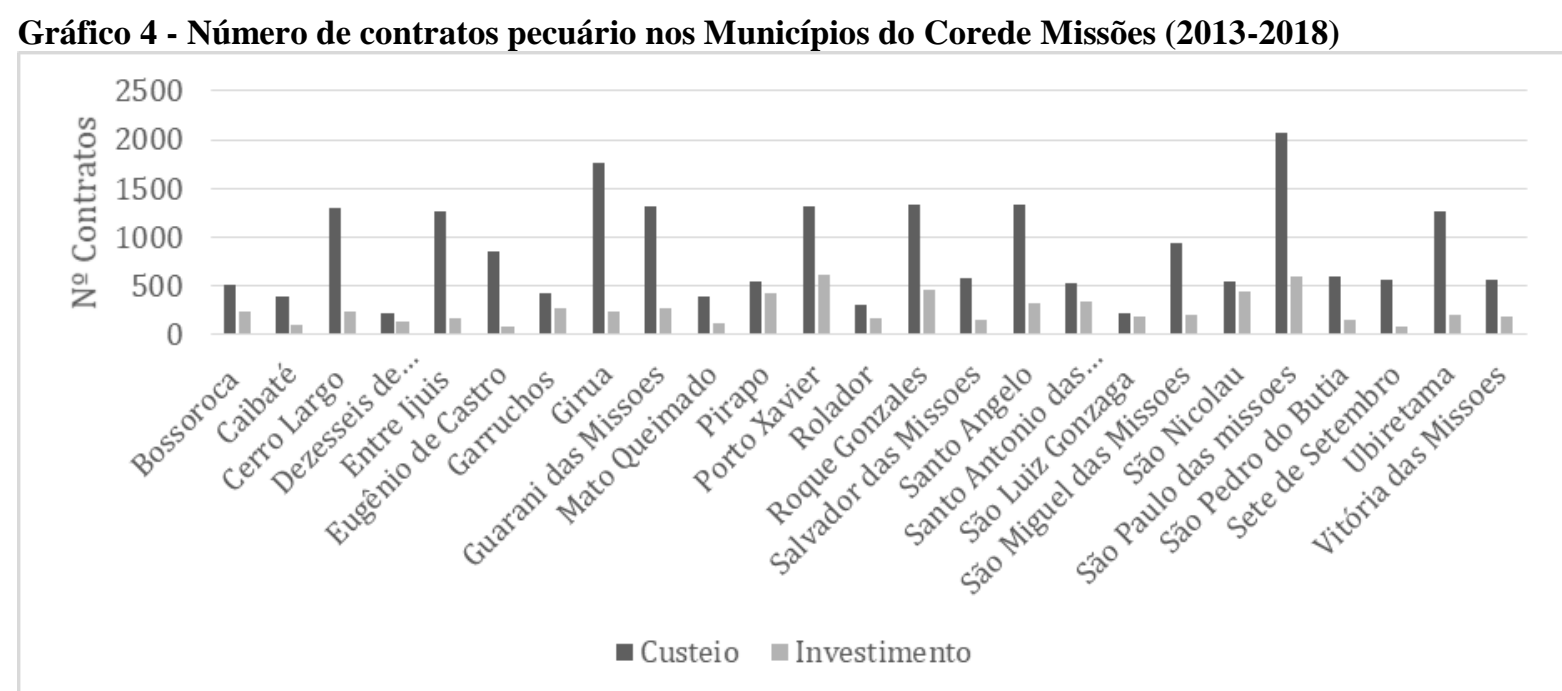

Fonte: Elaborado pelos autores (2020).

A partir da análise do Gráfico 4, percebe-se que o município que mais captou contratos (2.065) de custeio pecuário foi São Paulo das Missões, ao passo que Dezesseis de Novembro captou o menor número de contratações (225). A Prefeitura Municipal de São Paulo das Missões (2019) destaca que a criação tanto de rebanho bovino quanto leiteiro representa uma importante atividade desenvolvida pelo município, sendo regida pela Lei 1668/2019, que disponibiliza e afirma a concessão de incentivos. A média de contratações anuais no Corede Missões foi de 3.559. Já a média do estado foi de aproximadamente 41.849 por ano. Dessa forma, cabe destacar que o Corede Missões capta cerca de $8 \%$ dos contratos de custeio pecuário emitidos por ano no estado. A média de contratos por município do Corede Missões ficou em aproximadamente 134 contratos. Já a média estadual é de cerca de 84 contratos por município, ou seja, a Região das Missões apresenta uma média municipal de captação de contratos superior ao estado. 
O município que mais captou contratos (611) em investimento pecuário foi Porto Xavier, sendo que Eugênio de Castro captou o menor número de contratos (86 contratações). A média de contratos anuais nos municípios do Corede Missões, na modalidade de investimento pecuário, ficou em torno de 252 contratos por município, superior à média do estado que foi de 198 contratos por município.

\section{Gráfico 5 - Valor total captado para custeio e investimento pecuários (2013-2018)}

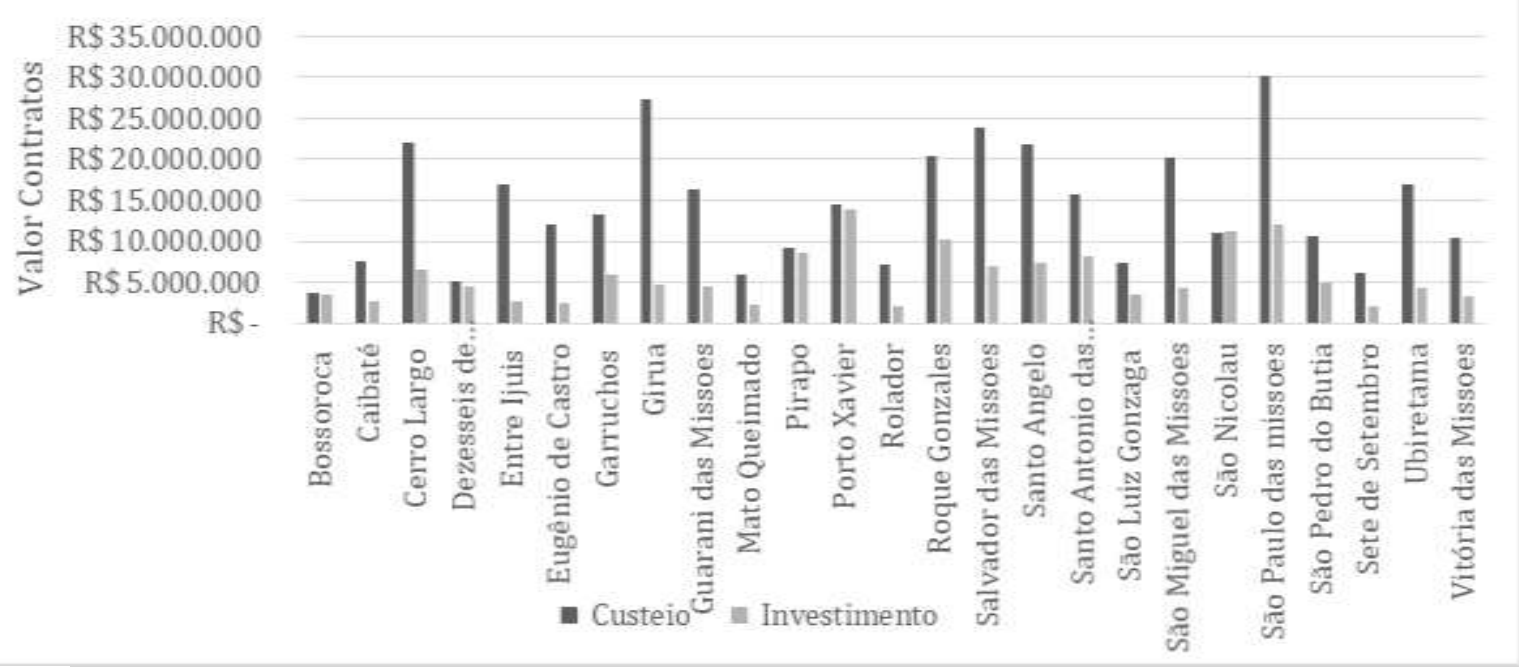

Fonte: Elaborado pelos autores (2020).

Com base no Gráfico 5, observa-se que o município que mais captou recursos em custeios pecuários, de 2013 a 2018, foi São Paulo das Missões (R \$ 30 milhões). Bossoroca foi o município que menos adquiriu fundos por meio de custeios pecuários, com um valor financiado de R\$ 3 milhões. O município que mais captou recursos em investimentos pecuários foi Porto Xavier, com mais de 13 milhões adquiridos. Por outro lado, Sete de Setembro foi o município que captou menos recursos nessa modalidade, 2 milhões de reais.

O Gráfico 6 ressalta os valores totais anuais captados pelos municípios do Corede Missões para custeio e investimento pecuário. Permite também observar que ocorreu a variação dos referidos valores durante os anos analisados. A variação para custeio pecuário foi de aproximadamente 24 milhões e de 4 milhões para investimento. 
Gráfico 6 - Valores pecuários captados anualmente no Corede Missões (2013 e 2018)

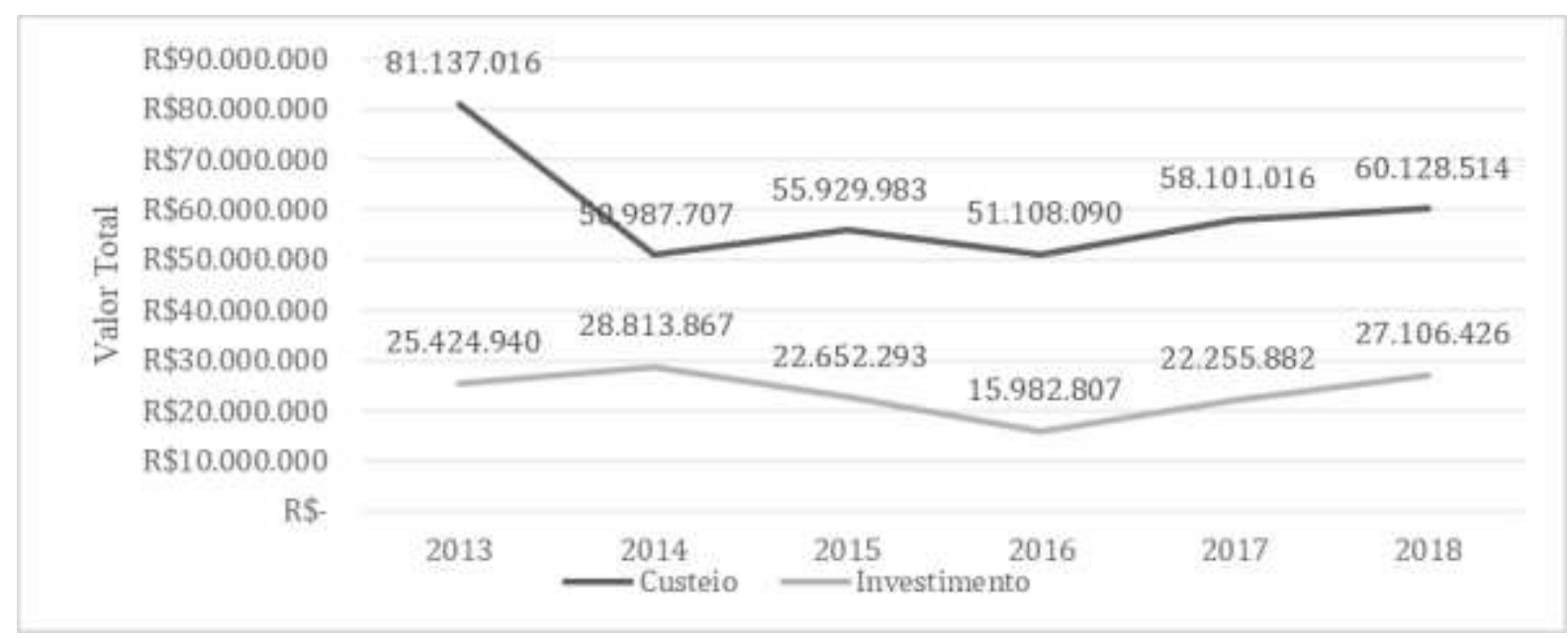

Fonte: Elaborado pelos autores (2020).

A média anual para custeio pecuário captada pelos municípios do Corede Missões ficou em torno de 59,5 milhões de reais, ou seja, obteve-se uma média de aproximadamente 2,3 milhões de reais por município e o valor médio por contrato aproximou-se de 16,7 mil reais. O Rio Grande do Sul, por sua vez, captou em média um valor aproximado de 835 milhões de reais, sendo que a média de recursos por município ficou em cerca de 1,7 milhões de reais. Já a média anual para investimento pecuário foi de 23,3 milhões de reais, sendo que a média de recursos captada por município ficou em aproximadamente 940 mil reais. Por outro lado, a média estadual de captação por ano ficou em torno de 471 milhões, sendo a média por município próxima a 949 mil.

A partir dos dados de valores e contratos para a atividade pecuária, destaca-se que os municípios beneficiados nesta modalidade diferem da modalidade agrícola, visto que tais municípios possuem menor extensão territorial, bem como acabam utilizando a área para atividades como a bovinocultura de leite. Por exemplo, conforme Censo agropecuário 2017 (IBGE, 2020), São Paulo das Missões possui 1.096 estabelecimentos agropecuários e uma área dos estabelecimentos de 18.914ha, com uma média de 17,25 hectares por estabelecimento, ao passo que em Giruá, um dos municípios mais beneficiados com a atividade agrícola, há 1.586 estabelecimentos utilizando 74.952 há, uma média de 47,2 hectares. 
Após o panorama geral de contratos e valores captados para a pecuária, procurou-se conhecer os produtos que foram contratados e seus respectivos valores. As Tabela 5 e 6 destacam os principais produtos financiados para o custeio pecuário, o número de contratos e valores, respectivamente.

Em tais tabelas, salienta-se que o custeio pecuário financia a região, em sua maioria bovinos 97,44\% (20.813), totalizando um valor aproximado de 332 milhões. O município que mais contratou para esta modalidade foi São Paulo das Missões, com 2.387 e um valor de 27 milhões de reais, seguido de Guarani das Missões, com 1.760 contratos e 14 milhões financiados e Santo Ângelo, com 1.327 contratos e um valor total de financiamentos de 21 milhões de reais.

Tabela 5 - Produtos Versus número de contratos (2013 a 2018) para custeio pecuário

\begin{tabular}{lccccccc}
\hline Produtos & 2013 & 2014 & 2015 & 2016 & 2017 & 2018 & Total \\
\hline Bovinos & 4.161 & 3.907 & 3.617 & 3.173 & 3.087 & 2.868 & 20.813 \\
Pastagem & 55 & 49 & 6 & 9 & 10 & 7 & 136 \\
Oculto & 38 & 38 & 29 & 45 & 29 & 40 & 219 \\
Avicultura & & & 5 & 4 & & 4 & 9 \\
Suínos & 56 & 22 & 18 & 12 & 30 & 44 & 182 \\
\hline Total & 4.310 & 4.016 & 3.675 & 3.243 & 3.156 & 2.959 & 21.359 \\
\hline
\end{tabular}

Fonte: Elaborado pelos autores (2020).

Tabela 6 - Produtos Versus valor captado (2013 a 2018) para custeio pecuário (em mil)

\begin{tabular}{lccccccc}
\hline Produtos & $2013 / \mathrm{R} \$$ & $2014 / \mathrm{R} \$$ & $2015 / \mathrm{R} \$$ & $2016 / \mathrm{R} \$$ & $2017 / \mathrm{R} \$$ & $2018 / \mathrm{R} \$$ & Total/R\$ \\
\hline Bovinos & 73.362 & 56.058 & 48.874 & 45.511 & 56.289 & 52.521 & 332.617 \\
Pastagem & 1.291 & 2.636 .468 & 40 & 70 & 132 & 57 & 4.229 \\
Oculto & 3.176 & 3.890 .853 & 6.486 & 885 & 812 & 1.019 & 16.271 \\
Avicultura & & & 107 & 106 & & & 214 \\
Suínos & 3.306 & 370.462 & 419 & 269 & 867 & 1.624 & 6.858 \\
\hline Total & 81.137 & 62.956 & 55.929 & 46.844 & 58.101 & 55.223 & 360.192 \\
\hline
\end{tabular}

Fonte: Elaborado pelos autores (2020).

Destaca-se a importância dos custeios pecuários para o Corede Missões, que captou aproximadamente 21.359 contratos e cerca de 350 milhões em custeio pecuário. Teve-se uma média anual de 3.559 contratos, com valor médio de $\mathrm{R} \$ 16.732,63$ cada, sendo que o produto com mais custeio pecuário foi o bovino. Para o Canal Rural (2015), na região das Missões são produzidos mensalmente em torno de 18 milhões litros de leite por mais de 10 
mil produtores, o que significa aproximadamente $\mathrm{R} \$ 16,5$ milhões mensais. Um fator bastante importante para a eficiência na produção leiteira é a alimentação dos rebanhos. Silva e Maixner (2015) apontam que o potencial genético dos animais é expresso quando a demanda de alimentos for atendida, o que explica os investimentos destinados a pastagem. Dessa forma, ressalva-se que o Corede Missões captou aproximadamente 1,5\% do valor total emitido em todo Brasil na modalidade de custeio pecuário.

As Tabela 7 e 8 explicitam os principais produtos financiados para investimento pecuário, o número de contratos e valores, respectivamente. Com isso, é possível notar que o maior número de contratos para investimento pecuário foi para o financiamento de bovinos (49,9\%). Foram 2.830 contratos e aproximadamente 69 milhões em recursos adquiridos. Porto Xavier foi o município que mais contratou a compra de bovinos, ou seja, foram 408 contratos e cerca de 6,5 milhões de reais, seguido por Pirapó, com 216 contratações e aproximadamente 5 milhões em recursos.

Tabela 2 - Produtos Versus número de contratos (2013 a 2018) para investimento pecuário

\begin{tabular}{|c|c|c|c|c|c|c|c|}
\hline Produtos & 2013 & 2014 & 2015 & 2016 & 2017 & 2018 & Total \\
\hline Bovinos & 873 & 675 & 452 & 308 & 247 & 275 & 2.830 \\
\hline Oculto & 256 & 241 & 200 & 188 & 185 & 203 & 1.273 \\
\hline $\begin{array}{l}\text { Máquinas, aparelhos } \\
\text { implementos }\end{array}$ & 300 & 188 & 113 & 57 & 59 & 36 & 753 \\
\hline Outros & 906 & 182 & 117 & 44 & 89 & 117 & 1.455 \\
\hline Total & 2.335 & 1.286 & 882 & 597 & 580 & 631 & 6.311 \\
\hline
\end{tabular}

Outros: Outras aplicações, Outros melhoramentos, Pastagem, Trator, Armazém, depósito ou galpão, Máquinas e implementos, Pescado, Outras máquinas, Proteção do Solo, Suínos, Correção Intensiva do Solo, Ovinos, Construção e reformas, Embarcação pequena, Camioneta, Embarcações, Outros sistemas de captação de água, Jipes, Prestação de assessoria técnica, Carretas.

Fonte: Elaborado pelos autores (2020). 
Tabela 3 - Produtos versus valor captado (2013 a 2018) para investimento pecuário (em mil)

\begin{tabular}{|c|c|c|c|c|c|c|c|}
\hline Produtos & 2013/R\$ & $2014 / \mathrm{R} \$$ & $2015 / \mathrm{R} \$$ & 2016/R\$ & $2017 / \mathrm{R} \$$ & $2018 / \mathrm{R} \$$ & Total \\
\hline Bovinos & 12.299 & 16.066 & 13.463 & 8.823 & 8.414 & 10.100 & 69.168 \\
\hline Oculto & 4.244 & 6.081 & 3.861 & 5.631 & 9.174 & 8.621 & 37.615 \\
\hline $\begin{array}{l}\text { Máquinas, } \\
\text { aparelhos e } \\
\text { implementos }\end{array}$ & 2.788 & 2.740 & 1.608 & 747 & 889 & 805 & 9.579 \\
\hline Suínos & & & 1.199 & & 495 & 3.051 & 4.746 \\
\hline $\begin{array}{l}\text { Outros } \\
\text { melhoramentos }\end{array}$ & 1.513 & 1.376 & 658 & 171 & & & 3.719 \\
\hline Trator & 272 & 484 & 741 & 480 & 221 & 1.237 & 3.439 \\
\hline Armazém & 728 & 224 & 50 & 38 & 97 & 1.213 & 2.352 \\
\hline $\begin{array}{l}\text { Máquinas e } \\
\text { Implementos }\end{array}$ & & & & & 782 & 1.518 & 2.301 \\
\hline $\begin{array}{l}\text { Outras } \\
\text { aplicações }\end{array}$ & 1.915 & 235 & & & & & 2.150 \\
\hline $\begin{array}{l}\text { Outras } \\
\text { máquinas }\end{array}$ & 165 & 345 & 487 & 68 & & & 1.066 \\
\hline Outros & 1.357 & 597 & 70 & 21 & 149 & 176 & 2.372 \\
\hline Total & 25.284 & 28.153 & 22.140 & 15.982 & 20.225 & 26.725 & 138.513 \\
\hline
\end{tabular}

Outros: Pastagem, Depósito ou galpão, Pescado, Proteção do Solo, Correção Intensiva do Solo, Ovinos, Construção e reformas, Embarcação pequena, Camioneta, Embarcações, Outros sistemas de captação de água, Jipes, Prestação de assessoria técnica, Carretas.

Fonte: Elaborado pelos autores (2020).

A segunda opção que mais captou contratos em investimento pecuário foi máquinas, aparelhos e instrumentos. Captaram-se 753 contratos e 9 milhões em recursos obtidos. $\mathrm{O}$ município que mais captou contratos para tal fim foi São Paulo das Missões, retendo 128 contratações e cerca de 1 milhão recursos, seguido por Santo Ângelo, que adquiriu 85 contratos e um valor de 855 mil reais.

Diante dos resultados expostos, é possível constatar que os municípios do Corede Missões captaram, entre 2013 e 2018, 6.311 contratos e cerca de R\$ 140 milhões em recursos em investimentos pecuários, sendo que os principais produtos custeados foram bovinos, máquinas e implementos, outros melhoramentos e aplicações. A Região das Missões captou, entre 2013 e 2018, cerca de $0,3 \%$ do total dos recursos captados em todo território brasileiro.

O elevado número de captação de contratos e recursos para a compra de bovinos ou atividades relacionadas indica a representatividade da atividade leiteira na região. Um projeto realizado pelo Sebrae, que tinha como objetivo aumentar a rentabilidade e a 
sustentabilidade em 65 propriedades da região, entre 2015 e 2018, demonstrou que apesar da crise no setor produtivo leiteiro durante período analisado, 55\% das empresas tiveram um aumento de $5 \%$ no faturamento, $83 \%$ das propriedades implementaram controles gerenciais, $28 \%$ delas atingiram um alto padrão de qualidade e $48 \%$ aumentaram o volume físico da produção (SEBRAE, 2019).

Com base nos dados salientados a respeito do custeio, investimento agrícola e pecuário, pode-se observar que nos seis anos de análise cerca de 2 bilhões de reais circularam nos municípios do Corede Missões, valor que tende a auxiliar na agricultura e pecuária do município, em especial nos produtos para as quais os valores foram destinados: cultura da soja e a bovinocultura. No entanto, tais valores têm significativa variação entre os municípios. Conforme DEEDADOS (FEE, 2020), o valor da produção de Soja no Corede Missões passou de 1bilhãoe m 2013 para 2 bilhões em 2018, o rendimento médio da cultura passou de $2.376 \mathrm{~kg} / \mathrm{ha}$ para $3.256 \mathrm{~kg} / \mathrm{ha}$, a quantidade produzida passou de 1.1 milhão de toneladas para 1,7 milhão de toneladas e a área plantada passou de 448 mil toneladas para 556 mil toneladas neste período de análise. Ainda em conformidade com a FEE, o valor da produção de leite, em 2013, foi de 185 milhões e, em 2016, foi de 308 milhões. Já a quantidade produzida passou de 209 milhões litros, em 2013, para 268 milhões de litros, em 2016, ao passo que o rebanho bovino na região, em 2013, era de 780 mil cabeças e passou para 771 mil cabeças, em 2016. Ademais, o índice de Desenvolvimento Socioeconômico do Corede Missões passou de 0,736, em 2013, para 0,742, em 2016, evidenciando uma pequena elevação dos indicadores Educação, Saúde e Renda, estando ainda em um nível médio de desenvolvimento. Assim, mesmo de forma singela, há a tendência de que os recursos do Pronaf estão contribuindo com uma melhoria nos dados socioeconômicos dos municípios do Corede Missões, em especial quanto aos dados econômicos das atividades agropecuárias.

O estudo constou que o Pronaf investimento e custeio para o setor agrícola e pecuário desempenha um papel importante no fomento da agricultura familiar nos municípios do Corede Missões, sendo que no período ocorreu o aumento da utilização do programa em número de contratos e recursos. São elementos que tenderam a modernizar o segmento, ampliar o emprego e a renda na economia agrícola, bem como estimular os produtos financiados. No entanto, tais conclusões precisam ser vistas com cautela, pois não 
há uma inferência técnica. Além disso, existe a variação dos dados entre os municípios que pode demonstrar a desigualdade entre eles. Ademais, há evidências que oferecem uma noção do comportamento da produção agrícola e pecuária da região estudada diante da política de crédito rural oriunda do Pronaf.

\section{CONSIDERAÇÕES FINAIS}

A criação e surgimento do Programa Nacional da Agricultura Familiar, em 1996, simboliza um processo de melhoria e acesso aos investimentos, sobretudo por parte da agricultura familiar. O programa tem figurado, ao longo do tempo, como uma das mais importantes políticas públicas que incide sobre o meio rural brasileiro, principalmente pelo fato de abranger a maioria dos municípios do país, além de ter oportunizado a democratização do acesso ao crédito e a visibilidade social de um público que, até então, sofria com a falta de reconhecimento e oportunidade. A variedade de modalidades para o Pronaf tem auxiliado os agricultores familiares no custeio e financiamento das atividades agrícolas e pecuárias, a fim de melhorar o cotidiano no meio rural.

Desse modo, o objetivo do estudo foi analisar as captações dos recursos e características dos contratos de custeio e investimento do Pronaf nos municípios do Corede Missões/ RS (2013-2018). Pode-se dizer que chegou a ser atingido, pois por meio do custeio agrícola foram captados 56.333 contratos e cerca de 1 bilhão de reais, sendo a produção de grãos a principal atividade financiada. Em relação ao custeio pecuário, captou-se 21.359 contratos e 350 milhões, sendo que a compra de bovinos foi a principal finalidade custeada. Já em relação ao investimento agrícola, observou-se que foram captados 10.129 contratos e absorvidos cerca de 470 milhões, sendo os principais produtos adquiridos as máquinas, os implementos e tratores. Em relação à captação de investimento pecuário, foram 6.311 contratos e cerca de R $\$ 140$ milhões tendo como principais produtos financiados os bovinos, máquinas e implementos e outros melhoramentos e aplicações. De tal forma, destaca-se que os investimentos e número de contratos sejam mais elevados quanto às atividades agrícolas em relação às atividades pecuárias.

Os recursos captados mostram que o Corede das Missões teve, nos seis anos analisados, um valor significativo para o desenvolvimento das atividades agrícolas e 
pecuárias, tais recursos estão sendo utilizados para aprimorar as atividades dos agricultores familiares beneficiados, elementos que podem estar promovendo melhoria nos indicadores econômicos da agropecuária desta região, a qual tem sua economia baseada neste setor e, de forma indireta, pode beneficiar os demais indicadores socioeconômicos. As atividades financiadas, mesmo tendo como foco os grãos, ressaltam a diversidade de atividades presentes nos municípios, constituindo uma característica da agricultura familiar.

Assim, o Pronaf é um programa do Estado que apoia o desenvolvimento rural sustentável e busca a garantia da segurança alimentar por meio do fortalecimento da agricultura, bem como do financiamento para os agricultores.

A principal limitação do estudo faz menção à dificuldade de acesso aos dados nacionais do Pronaf, em especial da Matriz de Dados do Crédito Rural. Para a realização de estudos futuros, sugere-se a comparação entre os recursos, contratos e produtos custeados ao Corede Missões, com os demais Coredes, como forma de visualizar as especificidades de captação de cada região do Rio Grande do Sul.

\section{REFERÊNCIAS}

BANCO CENTRAL DO BRASIL. Calculadora do Cidadão, 2019. Disponível em: < https://www.bcb.gov.br/acessoinformacao/calculadoradocidadao >. Acesso em: 16 maio 2019.

\section{BANCO CENTRAL DO BRASIL. Programa Nacional de Fortalecimento da} Agricultura Familiar - PRONAF, 2017. Disponível em:

<ttps://www.bcb.gov.br/acessoinformacao/legado?url=https:\%2F\%2Fwww.bcb.gov.br\%2F pre\%2Fbc_atende\%2Fport\%2FPRONAF.asp\#1>. Acesso em: 17 abr. 2019.

BARBOSA, A. S.; ALVES, T. W.; MASSUQUETTI, A. A Produção de Etanol no Brasil e no Estado do Rio Grande do Sul. In: SEMINÁRIO INTERNACIONAL SOBRE DESENVOLVIMENTO REGIONAL, 6, 2013, Santa Cruz do Sul. Anais eletrônicos... Disponível em: < https://www.unisc.br/site/sidr/2013/Textos/272-2.pdf>. Acesso em: 27 out. 2019.

BATISTA, H. R.; NEDER, H. D. Efeitos do Pronaf sobre a pobreza rural no Brasil (20012009). Revista de Economia e Sociologia Rural. Brasília, v. 52, n.1, p. 147-166, 2014. Disponível em: <http://www.scielo.br/scielo.php?script=sci_arttext\&pid=S0103$20032014000600008 \& \operatorname{lng}=$ pt\&tlng=pt $>$. Acesso em: 4 abr. 2019.

BRAMBILlA, M. A.; MICHELLON, E. Análise Espacial da Agricultura Familiar e do Pronaf da Região Sul. In: CONGRESSO DA SOCIEDADE BRASILEIRA DE 
ECONOMIA, ADMINISTRAÇÃO E SOCIOLOGIA RURAL: INOVAÇÃO, EXTENSÃO E COOPERAÇÃO PARA O DESENVOLVIMENTO, 55, 2017, Santa Maria. Anais Eletrônicos... Santa Maria, UFSM, 2017. Disponível em:

<http://icongresso.itarget.com.br/tra/arquivos/ser.7/1/7418.pdf>. Acesso em: 16 abr. 2019.

BRASIL. Lei $\mathbf{n}^{\circ}$ 11.326, de 24 de julho de 2006. Estabelece as diretrizes para a formulação da Política Nacional da Agricultura Familiar e Empreendimentos Familiares Rurais. Diário Oficial [da] República Federativa do Brasil, 25 jul. 2006. Disponível em:

<http://www.planalto.gov.br/ccivil_03/_Ato2004-2006/2006/Lei/L11326.htm>. Acesso em: 11 abr. 2019.

CANAL RURAL. Encontro debate futuro da bacia leiteira das Missões (RS), 2015. Disponível em: $<$ https://canalrural.uol.com.br/noticias/encontro-debate-futuro-bacialeiteira-das-missoes-58713/>. Acesso em: 14 out. 2019.

CAPELlESSO, A. J.; CAZELlA, A. A.; BÚRIGO, F. L. Evolução do Pronaf Crédito no Período 1996-2013: redimensionando o acesso pelos cadastros de pessoa física. Revista de Economia e Sociologia Rural. Brasília, v. 56, n. 3, p 437-450, 2018. Disponível em:< http://www.scielo.br/pdf/resr/v56n3/1806-9479-resr-56-03-437.pdf >. Acesso em: 18 out. 2019.

DALCIN, D. et al. A Captação de Recursos e Contratos do Pronaf no Rio Grande do Sul: um Estudo dos Coredes (2013 - 2016). In: SEMINÁRIO INTERNACIONAL SOBRE DESENVOLVIMENTO REGIONAL, 9, 2017, Santa Cruz do Sul. Anais eletrônicos.... Disponível em:

<https://online.unisc.br/acadnet/anais/index.php/sidr/article/view/16491/4194>. Acesso em: 8 abr. 2019.

FEE - FUNDAÇÃO DE ECONOMIA E ESTATÍSTICA. DEE dados: Dados Socioeconômicos do Corede Missões, 2020. Disponível em: http://feedados.fee.tche.br/feedados>. Acesso em: 13 jun. 2020.

\section{FEE - FUNDAÇÃO DE ECONOMIA E ESTATÍSTICA. Perfil socioeconômico do} Corede Missões, 2015. Disponível em:

$<$ https://planejamento.rs.gov.br/upload/arquivos/201603/28140705-perfis-regionais-2015missoes.pdf >. Acesso em: 4 abr. 2019.

FEE - FUNDAÇÃO DE ECONOMIA E ESTATÍSTICA. Perfil Socioeconômico: Índice de Desenvolvimento Socioeconômico (Idese) dos Coredes do Rio Grande do Sul, 2013. Disponível em: < https://arquivofee.rs.gov.br/indicadores/indice-de-desenvolvimentosocioeconomico/serie-historica-nova-

metodologia/ ?unidade $=$ coredes $\&$ ano $=2013 \&$ letra $=\&$ ordem $=$ coredes $>$. Acesso em: 13 jun. 2020.

GIL, A. C. Pesquisa Social. In: GIL, A. C. Métodos e Técnicas de Pesquisa Social. São Paulo: Atlas, 2008. cap. 3, p 26-32. Disponível em: 
<https://ayanrafael.files.wordpress.com/2011/08/gil-a-c-mc3a9todos-e-tc3a9cnicas-depesquisa-social.pdf >. Acesso em: 20 abr. 2019.

GOVERnO DO ESTADO DO RIO GRANDE DO SUL. Plano Estratégico de

Desenvolvimento da Região das Missões: 2015-2030. 2017. Disponível em:

<https://planejamento.rs.gov.br/upload/arquivos/201710/09152209-plano-missoes.pdf >. Acesso em: 27 abr. 2020.

GUEDES, T. A. Estatística Descritiva, 2005. Disponível em:

<http://www.each.usp.br/rvicente/Guedes_etal_Estatistica_Descritiva.pdf >. Acesso em: 12 maio 2019.

IBGE - INSTITUTO BRASILEIRO DE GEOGRAFIA E ESTATÍSTICA. IBGE Cidades, 2020. Disponível em: <https://cidades.ibge.gov.br/> Acesso em: 12 jun. 2020.

KAGEYAMA, A. A. Rural e Ruralidade. In: KAGEYAMA, A. A. Desenvolvimento Rural. Conceitos e aplicação ao caso brasileiro. Porto Alegre, UFRGS, 2008. cap.1, p.1536.

MARQUES, C. B.; SIEDENBERG, D. R.; SANTOS, C. H. S. O papel das políticas públicas no desenvolvimento local. São José do Norte-RS. Revista de Políticas Públicas. São Luis, v. 12, n. 2, p. 57-64, 2008. Disponível em:

<http://www.periodicoseletronicos.ufma.br/index.php/rppublica/article/view/3851/1989>. Acesso em: 5 abr. 2019.

MINISTÉRIO DA AGRICULTURA, PECUÁRIA E ABASTECIMENTO. Crédito Rural, 2019. Disponível em:< http://www.agricultura.gov.br/assuntos/politica-agricola/creditorural>. Acesso em: 22 out.2019.

OLALDE, A. R.; SANTOS, I. de J.; SANTOS, E. O PRONAF e as desigualdades na agricultura familiar. In: CONGRESSO DA SOCIEDADE BRASILEIRA DE ECONOMIA, ADMINISTRAÇÃO E SOCIOLOGIA RURAL: Conhecimentos para Agricultura do Futuro. 45, 2007. Londrina. Anais Eletrônicos...Londrina, UEL, 2007. Disponível em:< http://www.sober.org.br/palestra/6/938>. Acesso em: 7 out. 2019.

PREFEITURA MUNICIPAL DE GIRUÁ. Giruá Capital da Produtividade, 2019. Disponível em: < https://www.girua.rs.gov.br/site/conteudos/154-capital-da-produtividade>. Acesso em: 22 out. 2019.

PREFEITURA MUNICIPAL DE SÃO PAULO DAS MISSÕES. Lei 1668/2019. Dispõe sobre o Programa de Inseminação Artificial e a Concessão de Incentivos ao Rebanho Bovino Leiteiro e Consulta Médico Veterinário, e dá outras Providências. 2019. Disponível em:< https://www.saopaulodasmissoes.rs.gov.br/site/leis/52358-lei-n-16682019---dispoesobre-o-programa-de-inseminacao-artificial-e-a-concessao-de-incentivos-ao>. Acesso em: 5 out. 2019. 
SCHNEIDER, S.; GRISA, C. In: GRISA, C.; SCHNEIDER, S. (Orgs.). Políticas Públicas de Desenvolvimento Rural no Brasil. Porto Alegre: UFGRS, 2015, p.14-19. Disponível em: <http://aspta.org.br/wp-content/uploads/2015/10/Pol\%C3\%ADticas-P\%C3\%BAblicasde-Desenvolvimento-Rural-no-Brasil.pdf>. Acesso em: 17 abr. 2019.

\section{SEBRAE. Produtores de leite apresentam resultados sustentáveis na região das}

Missões, 2019. Disponível em:<https://sebraers.com.br/produtores-de-leite-apresentamresultados-sustentaveis-na-regiao-das-missoes/>. Acesso em: 10 out. 2019.

SILVA, F. F. Distribuição de Crédito para Agricultura Familiar: um estudo do Pronaf a partir de um indicador de Desenvolvimento Rural. 2006. 250f. Dissertação (Mestrado em Economia). Programa de Pós-Graduação em Economia, Universidade Federal de Uberlândia, Uberlândia, 2006. Disponível em:

http://reformaagrariaemdados.org.br/sites/default/files/2006\%20Fernanda\%20Faria\%20Silv a.pdf>. Acesso em: 20 out. 2019.

SILVA, G. M. da.; MAIXNER, A. R. Manejo de Pastagens para Gado Leiteiro, 2015. Disponível em: https://ainfo.cnptia.embrapa.br/digital/bitstream/item/137071/1/SilvaMaixner.pdf>. Acesso em: 8 out. 2019.

SOUZA, P. M. de et al. A Distribuição dos Contratos de Crédito do Pronaf entre as Unidades da Federação no Período de 1999 a 2010. Revista Econômica do Nordeste. Fortaleza, v. 44, n.1, p. 27-44, 2013. Disponível em:

<https://ren.emnuvens.com.br/ren/article/view/4>. Acesso em: 6 abr. 2019.

SPOLADOR, H. F. S.; LIMA, R. A. de S. Evolução da distribuição de crédito agrícola no Brasil, entre Unidades da Federação, no período 2000 a 2007. In: CONGRESSO DA SOCIEDADE BRASILEIRA DE ECONOMIA, ADMINISTRATAÇÃO E SOCIOLOGIA RURAL: Desenvolvimento Rural e Sistemas Agroalimentares: os agronegócios no contexto de integração das nações, 2009. Porto Alegre. Anais eletrônicos... Porto Alegre, UFGRS, 2009. 